\title{
MET NP_000236.2:p.H1094Y
}

National Cancer Institute

\section{Source}

National Cancer Institute. MET NP 000236.2:p.H1094Y. NCI Thesaurus. Code C162290.

A change in the amino acid residue at position 1094 in the hepatocyte growth factor receptor protein where histidine has been replaced by tyrosine. 